\title{
Liver injury on admission linked to worse outcomes in COVID-19: an analysis of 14,138 patients
}

\author{
Harleen Kaur Chela ${ }^{1 \#}$, Erin M. Tallon ${ }^{2 \#}$, William Baskett ${ }^{2}$, Karthik Gangu ${ }^{3}$, Veysel Tahan ${ }^{1}$, \\ Chi-Ren Shyu ${ }^{2,4}$, Ebubekir Daglilar ${ }^{1}$
}

${ }^{1}$ Division of Gastroenterology, Department of Medicine, University of Missouri-Columbia, Columbia, MO, USA; ${ }^{2}$ Institute for Data Science and Informatics, University of Missouri-Columbia, Columbia, MO, USA; ${ }^{3}$ Division of Hospital Medicine, Department of Medicine, University of Missouri-Columbia, Columbia, MO, USA; ${ }^{4}$ Electrical Engineering and Computer Science Department, University of Missouri-Columbia, Columbia, MO, USA

Contributions: (I) Conception and design: HK Chela, E Daglilar, EM Tallon; (II) Administrative support: E Daglilar, V Tahan, CR Shyu, K Gangu; (III) Provision of study materials or patients: EM Tallon, W Baskett, CR Shyu; (IV) Collection and assembly of data: EM Tallon, W Baskett, HK Chela, E Daglilar; (V) Data analysis and interpretation: All authors; (VI) Manuscript writing: All authors; (VII) Final approval of manuscript: All authors.

\#These authors contributed equally to this work and should be considered as co-first authors.

Correspondence to: Harleen Kaur Chela, MD. Gastroenterology Fellow, Division of Gastroenterology, Department of Medicine, University of Missouri-Columbia, One Hospital Drive, CE 405, DC 043.00, Columbia, MO 65212, USA. Email: chelah@health.missouri.edu.

Background: Infection with the SARS-CoV-2 virus, which can result in hepatic inflammation and injury that varies from mild to severe and potentially acute fulminant liver injury, may be associated with poor outcomes. Our aims were to: (I) assess baseline clinical and demographic characteristics in patients with coronavirus disease 2019 (COVID-19) who did and did not have abnormalities in liver chemistries [alkaline phosphatase (ALP), aspartate aminotransferase (AST), alanine aminotransferase (ALT), and total bilirubin (Tbili)] and (II) evaluate associations between abnormalities in liver chemistries and the primary outcomes of in-hospital death, intubation, and hospital length of stay (LOS).

Methods: In this nationwide retrospective cohort study of 14,138 patients, we analyzed associations between abnormalities in liver chemistries (ALT, AST, ALP, and Tbili) and mortality, intubation, and prolonged hospital LOS in patients with laboratory-confirmed COVID-19. We used Pearson's chi-squared tests to detect significant differences in categorical variables for patients with and without abnormal liver chemistries. Welch's two-sample $t$-tests were used to make comparisons of liver chemistry (ALT, AST, ALP, Tbili) and serum albumin results. All other continuous variables were analyzed using independent samples $t$-tests. A P value of $<0.05$ was considered significant.

Results: Propensity score matching demonstrated that abnormalities in liver chemistries at admission are significantly associated with increased risk for mortality (RR 1.70) and intubation (RR 1.44) in patients with COVID-19. Elevated AST is the liver chemistry abnormality associated with the highest risk for mortality (RR 2.27), intubation (RR 2.12), and prolonged hospitalization (RR 1.19). Male gender, pre-existing liver disease, and decreased serum albumin are also significantly associated with severe outcomes and death in COVID-19.

Conclusions: Routine liver chemistry testing should be implemented and used for risk stratification at the time of COVID-19 diagnosis.

Keywords: Health outcomes; liver injury; liver disease; coronavirus disease 2019 (COVID-19); SARS-CoV-2

Received: 30 July 2021; Accepted: 04 November 2021; Published: 25 January 2023.

doi: $10.21037 /$ tgh-21-94

View this article at: https://dx.doi.org/10.21037/tgh-21-94 


\section{Introduction}

Spread of the SARS-CoV-2 virus occurred rapidly across the globe, resulting in one of the most challenging pandemics of the modern era (1). Despite the acquisition of a significant amount of knowledge about this peculiar virus, we continue to uncover new information. It targets not only the respiratory system but other organs as well including the liver (2). Given the potential for involvement of multiple systems, it is important for providers to recognize extra-pulmonary manifestations. The impact of coronavirus disease 2019 (COVID-19) on the medical and non-medical realms of humanity has been profound, and the efforts to overcome the pandemic continue to be underway with hope emerging with the arrival of vaccines (3). An abundance of information regarding the impact of the virus on the respiratory system has become available. The implications for other organs such as the liver are less well studied in comparison to the lungs though a plethora of studies has emerged over the past year with attempts to further solidify the effects on organs such as the liver. The impact on the liver can be variable and the degree of liver injury can vary, though patients may present with only mild abnormalities in liver chemistries. In this nation-wide multicenter study, we investigated liver chemistry abnormalities present on admission and the impact of those abnormalities on mortality, intubation, and hospital length of stay (LOS). Baseline characteristics of patients with abnormalities in liver chemistry are also evaluated with certain factors linked to worse outcomes. We present the following article in accordance with the STROBE reporting checklist for cohort studies (available at https://tgh.amegroups.com/ article/view/10.21037/tgh-21-94/rc).

\section{Methods}

\section{Objectives}

Our objectives were to (I) assess baseline clinical and demographic characteristics in patients with COVID-19 infection who had and did not have abnormalities in liver chemistries [alkaline phosphatase (ALP), aspartate aminotransferase (AST), alanine aminotransferase (ALT), and total bilirubin (Tbili)] and (II) evaluate associations between abnormalities in liver chemistries and the primary outcomes of in-hospital death, intubation, and hospital LOS.

We conducted a retrospective cohort study using the Cerner Real-World Data ${ }^{\mathrm{TM}}$ (CRWD) de-identified COVID-19 patient cohort (4). CRWD was extracted from the electronic medical record (EMR) of hospitals with which Cerner had a data use agreement. All authors had access to the study data and reviewed and approved the final manuscript.

\section{Ethical approval statement}

The University of Missouri Institutional Review Board (Federalwide Assurance ID: FWA00002876) deemed this study of de-identified patient data to not constitute human subjects research; therefore, direct informed consent from individual patients was not required (IRB \#2034442). The study was conducted in accordance with the Declaration of Helsinki (as revised in 2013).

\section{Data source and participants}

The December 2020 version (the 2020Q3 CRWD COVID database release) of Cerner's COVID-19 patient cohort contains EMR data from 87 U.S.-based health systems from December 2019 through part of September 2020. Information about the more than 100 demographic, clinical, and non-clinical variables included in the dataset has been previously published (5).

We limited our analysis to the first encounter at which each patient had a lab test with a positive result consistent with COVID-19 infection. Logical Observation Identifiers Names and Codes (LOINC) terms used to define SARS$\mathrm{CoV}-2$ infection are in Table S1. Within this patient subset, we identified patients who had a documented laboratory result for ALP, AST, ALT, and Tbili during the 24-hour before or after the documented start time of the COVID encounter. LOINC codes used to identify liver chemistry test results are in Table S2. Patients who did not have documented laboratory results for all four liver chemistries within 24 hours of the start time of the COVID encounter were excluded. Figure 1 contains a flow diagram depicting patient selection and inclusion criteria.

We categorized patients into two groups, based on whether they did or did not have at least one abnormal liver chemistry result within 24 hours of the start time of the COVID encounter. Thresholds used to define liver chemistry abnormalities were ALP $>105 \mathrm{U} / \mathrm{L}$, AST $>40 \mathrm{U} / \mathrm{L}$, ALT $>40 \mathrm{U} / \mathrm{L}$, and Tbili $>1.2 \mathrm{mg} / \mathrm{dL}(6,7)$. International Classification of Diseases, Ninth and Tenth Revision, Clinical Modification (ICD-9-CM and ICD-10-CM) diagnosis codes were used to identify patients who were associated with at least one ICD code indicative of any of 




Figure 1 Flow diagram depicting patient selection and inclusion criteria. ALP, alkaline phosphatase; ALT, alanine aminotransferase; AST, aspartate aminotransferase; COVID-19, coronavirus disease 2019.

the following conditions: diabetes mellitus (DM), chronic obstructive pulmonary disease (COPD), coronary artery disease (CAD), liver disease, history of nicotine dependence or exposure to environmental tobacco smoke, malignancy, heart failure (HF), and chronic kidney disease or end-stage renal failure (CKD-ESRD) (see Table S3). Case definitions and codes used to denote the primary outcomes of inhospital death, mechanical ventilation, and hospital LOS are in Table S4. Hospital LOS was grouped into two categories: LOS $\leq 3$ days and LOS $>3$ days. We used raw or calculated body mass index (BMI) measurements documented within 6 months of the COVID encounter to categorize patients as obese $(\mathrm{BMI} \geq 30)$ or not obese (BMI $<30)$. Medication data were used to identify patients who had been prescribed an oral proton pump inhibitor (PPI) or $\mathrm{H} 2$ blocker during the 60 days prior to the COVID encounter. Medication names and search terms for PPIs and H2 blockers are in
Tables S5,S6. Serum albumin laboratory results were used to identify patients who did and did not have decreased serum albumin $(<3.5 \mathrm{~g} / \mathrm{dL})$ (see Table S2). Patients with missing data for any of the covariates or outcomes of interest were excluded from analysis.

\section{Statistical analysis}

Analyses were conducted on Cerner's HealtheDataLab platform, a data science ecosystem hosted by Amazon Web Services (AWS) (8). The analytics engine powering the HealtheDataLab platform is Apache Spark version 2.4.4 (Apache Software Foundation, Wilmington, DE). Data extraction and analyses were performed using Python version 3.7.6 (Python Software Foundation) and $\mathrm{R}$ version 3.6.3 (R Foundation for Statistical Computing, Vienna, Austria). 
We used Pearson's chi-squared tests to detect significant differences in categorical variables for patients with and without abnormal liver chemistries. Welch's two-sample $t$-tests were used to make comparisons of liver chemistry (ALT, AST, ALP, Tbili) and serum albumin results. All other continuous variables were analyzed using independent samples $t$-tests. A P value of $<0.05$ was considered significant.

Retrospective analysis of two patient groups (i.e., patients with and without abnormal liver chemistry results) can be adversely impacted by dissimilarities existing between the two groups at baseline. Propensity score (PS) analysis is used to reduce this potential confounding. In PS analysis, a propensity score is calculated for each patient via logistic regression. In this study, the propensity score reflects the conditional probability that a given patient has at least one abnormal liver chemistry result (ALT, AST, ALP, and/or Tbili) given the patient's values for the other covariates used to calculate the PS (9). The distribution of the covariates is equal for patients in each group who have the same propensity score (10). By using propensity scores to match patients across each group, we control for baseline differences in the covariates and can more accurately estimate the effect of the variable of interest (i.e., abnormalities in liver chemistries) on the outcomes of interest (9).

To perform PS analysis, we first categorized each patient into one of two groups: (I) patients with one or more abnormal liver chemistry results $(n=8,883)$, or (II) patients with no abnormal liver chemistry results $(\mathrm{n}=5,255)$. Covariates used to calculate a propensity score for each patient included the following: age (as a quantitative variable); gender; race/ethnicity [grouped into the following categories: (I) non-Hispanic White; (II) non-Hispanic Black; (III) Hispanic; and (IV) Asian American/Pacific Islander, American Indian/Alaska Native, or non-Hispanic Other]; blood type; BMI (as a quantitative variable); history of smoking or exposure to tobacco smoke; presence of each of seven different comorbidities, including DM, COPD, $\mathrm{CAD}$, malignancy, HF, CKD-ESRD, and pre-existing liver disease; serum albumin; recent use of an $\mathrm{H} 2$ blocker; and recent use of a PPI. We used MatchIt to calculate a PS for each patient via logistic regression. We then used the full matching algorithm in MatchIt to match each patient with at least one abnormal liver chemistry result with one or more individuals who had no abnormal liver chemistry results. Patients who did not have liver chemistry abnormalities were assigned weights proportional to those patients who did have liver chemistry abnormalities. To optimize the matching process and reduce bias, we specified a caliper of
0.25 of the standard deviation of the logit (9). After using propensity scores to match patients across each group, we used stepwise (bidirectional elimination) logistic regression to estimate the effect of abnormalities in liver chemistries on the risk of all three outcomes (death, intubation, and longer hospital LOS). We then used rbounds to conduct Rosenbaum's sensitivity tests to quantify the sensitivity of our findings to hidden bias resulting from unmeasured covariates.

Lastly, we conducted separate analyses that used stepwise (bidirectional elimination) logistic regression, adjusting only for elevations in each of the four liver chemistries, to analyze associations between elevated liver chemistries and risk of experiencing each outcome.

\section{Results}

\section{Baseline demographics and characteristics of liver injury}

Among 102,438 patients who had an encounter associated with laboratory-confirmed COVID-19 infection, a total of 14,138 patients met inclusion criteria, had no missing data for the covariates of interest, and had no missing data for all three outcomes (see Figure 1). Demographic and clinical characteristics of these patients are outlined in Table 1.

We compared the patient characteristics in the group with liver abnormalities to those in the group lacking the abnormalities. Median age of patients with derangements in liver chemistries was somewhat lower [61.0 (IQR, 47.0-72.0) vs. 64.0 (IQR, 48.0-76.0) years; $\mathrm{P}<0.001$ ]. Male gender was more frequently associated with abnormalities in liver chemistries $(53.1 \%$ vs. $42.3 \%, \mathrm{P}<0.001)$. NonHispanic White individuals accounted for the greatest number of total patients $(\mathrm{n}=4,708,33.3 \%)$ in the study, followed by Hispanic White $(\mathrm{n}=4,437,31.4 \%)$, NonHispanic Black $(\mathrm{n}=2,436,17.2 \%)$, Hispanic Other $(\mathrm{n}=1,486$, $10.5 \%)$, American Indian or Alaska Native ( $\mathrm{n}=447,3.2 \%)$, Asian or Pacific Islander ( $\mathrm{n}=334,2.4 \%)$, Non-Hispanic Other $(\mathrm{n}=239,1.7 \%)$, and Hispanic Black $(\mathrm{n}=51,0.4 \%)$. Figure 2 shows the proportion of patients in each racial/ ethnic group who had liver abnormalities. Blood type $\mathrm{O}_{+}$ was the most common blood group type in these patients $(\mathrm{n}=6,616,46.8 \%)$, followed by blood types $\mathrm{A}+(\mathrm{n}=4,380$, $31.0 \%)$ and $\mathrm{B}+(\mathrm{n}=1,581,11.2 \%)$.

We also evaluated the presence of comorbidities such as obesity (defined as BMI $\geq 30 \mathrm{~kg} / \mathrm{m}^{2}$ ), history of nicotine dependence or exposure to environmental tobacco smoke, DM, COPD, CAD, malignancy, HF, CKD-ESRD, and liver 
Table 1 Demographic and clinical characteristics of patients with and without abnormal liver chemistries

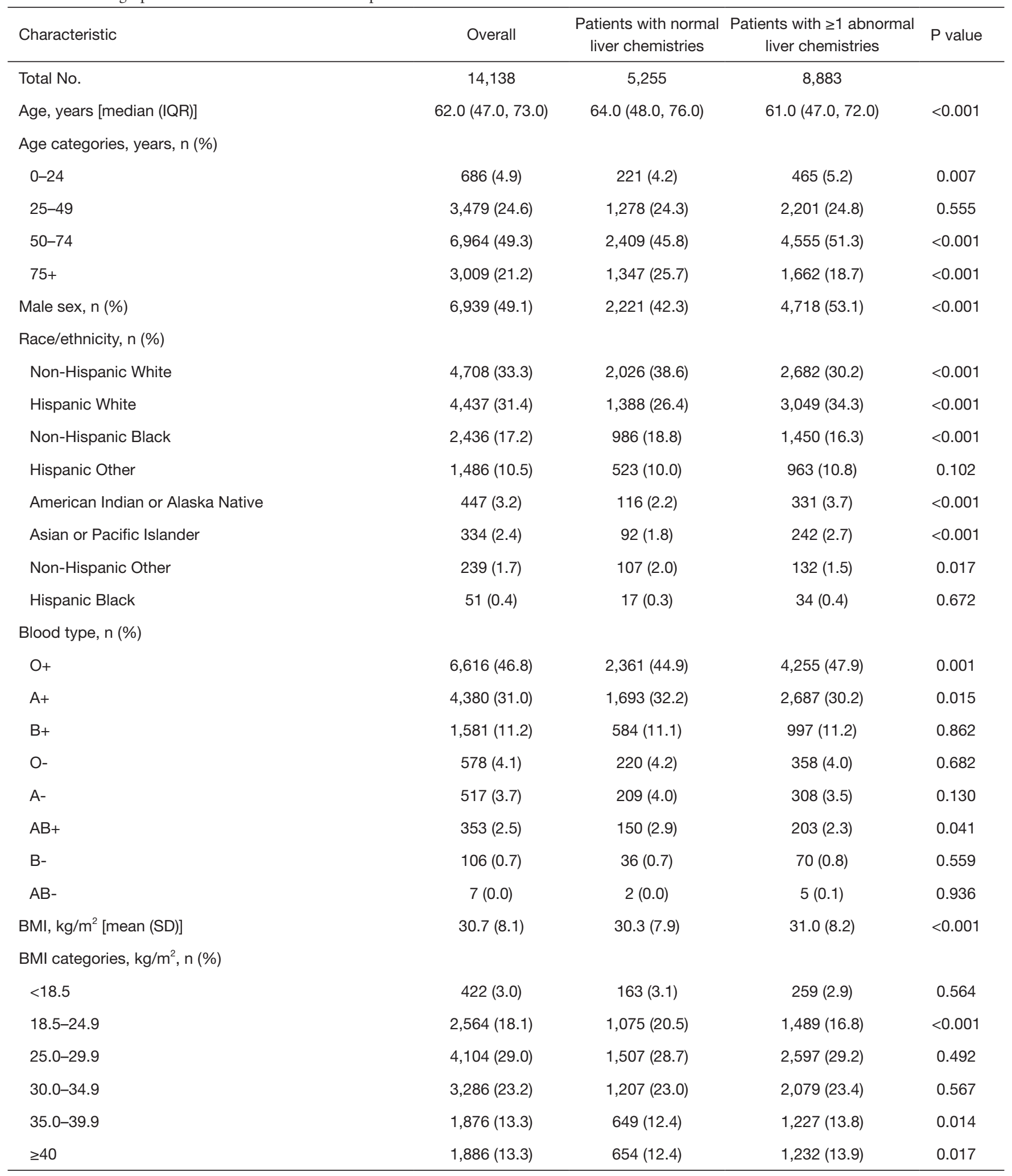

Table 1 (continued) 
Table 1 (continued)

\begin{tabular}{|c|c|c|c|c|}
\hline Characteristic & Overall & $\begin{array}{l}\text { Patients with normal } \\
\text { liver chemistries }\end{array}$ & $\begin{array}{l}\text { Patients with } \geq 1 \text { abnormal } \\
\text { liver chemistries }\end{array}$ & $P$ value \\
\hline $\begin{array}{l}\text { History of nicotine dependence or exposure to tobacco } \\
\text { smoke, } n(\%)\end{array}$ & 4,962 (35.1) & $1,924(36.6)$ & $3,038(34.2)$ & 0.004 \\
\hline Diabetes mellitus, $\mathrm{n}(\%)$ & $6,620(46.8)$ & $2,450(46.6)$ & $4,170(46.9)$ & 0.724 \\
\hline Chronic obstructive pulmonary disease, $\mathrm{n}(\%)$ & $2,060(14.6)$ & $921(17.5)$ & $1,139(12.8)$ & $<0.001$ \\
\hline Malignancy, n (\%) & $2,092(14.8)$ & $858(16.3)$ & $1,234(13.9)$ & $<0.001$ \\
\hline Heart failure, $\mathrm{n}(\%)$ & $3,023(21.4)$ & $1190(22.6)$ & $1,833(20.6)$ & 0.005 \\
\hline Chronic kidney disease/end-stage renal disease, n (\%) & $3,859(27.3)$ & $1510(28.7)$ & $2,349(26.4)$ & 0.003 \\
\hline Liver disease, $\mathrm{n}(\%)$ & $2,485(17.6)$ & $668(12.7)$ & $1,817(20.5)$ & $<0.001$ \\
\hline NASH/fatty liver disease, n (\%) & $1,085(7.7)$ & $288(5.5)$ & $797(9.0)$ & $<0.001$ \\
\hline Other liver disease, n (\%) & $1,468(10.4)$ & $349(6.6)$ & $1,119(12.6)$ & $<0.001$ \\
\hline Albumin, g/dL [mean (SD)] & $3.3(0.7)$ & $3.4(0.6)$ & $3.2(0.7)$ & $<0.001$ \\
\hline Albumin $<3.5 \mathrm{~g} / \mathrm{dL}, \mathrm{n}(\%)$ & $8,407(59.5)$ & $2,687(51.1)$ & $5,720(64.4)$ & $<0.001$ \\
\hline ALT, U/L [median (IQR)] & $28.0(18.0,47.0)$ & $19.0(13.0,25.0)$ & $41.0(25.0,64.0)$ & $<0.001$ \\
\hline AST, U/L [median (IQR)] & $38.0(25.0,60.0)$ & $25.0(19.0,32.0)$ & $52.0(39.0,78.0)$ & $<0.001$ \\
\hline ALP, U/L [median (IQR)] & $81.0(64.0,109.0)$ & $71.0(58.0,85.0)$ & $95.0(68.0,132.0)$ & $<0.001$ \\
\hline Intubated, n (\%) & 2,306 (16.3) & $557(10.6)$ & 1,749 (19.7) & $<0.001$ \\
\hline Length of stay $>3$ days, $n(\%)$ & $10,267(72.6)$ & $3,472(66.1)$ & $6,795(76.5)$ & $<0.001$ \\
\hline
\end{tabular}

ALP, alkaline phosphatase; ALT, alanine aminotransferase; AST, aspartate aminotransferase; BMI, body mass index; g/dL, grams per deciliter; H2 blocker, histamine 2 receptor agonist; IQR, interquartile range; $\mathrm{kg} / \mathrm{m}^{2}$, kilograms per meter squared; mg/dL, milligrams per deciliter; NASH, nonalcoholic steatohepatitis; PPI, proton pump inhibitor; SD, standard deviation; U/L, units per liter.

disease; other factors included recent prescriptions for a PPI or H2 blocker (see Table 1). Figure 3 shows the proportion of patients with and without liver abnormalities who were diagnosed with each comorbid condition. The comorbidity most commonly seen in this patient population was obesity $(\mathrm{n}=7,048,49.8 \%)$, followed by diabetes $(\mathrm{n}=6,620,46.8 \%)$, history of nicotine dependence or exposure to tobacco smoke $(\mathrm{n}=4,962,35.1 \%)$, CAD ( $\mathrm{n}=4,086,28.9 \%)$, CKD/
$\operatorname{ESRD}(\mathrm{n}=3,859,27.3 \%), \operatorname{HF}(\mathrm{n}=3,023,21.4 \%)$, liver disease $(n=2,485,17.6 \%)$, malignancy $(n=2,092,14.8 \%)$ and COPD ( $n=2,060,14.6 \%)$. The only co-morbidities that were more prevalent in the group with the abnormal liver chemistries were obesity $(51.1 \%$ vs. $47.8 \%, \mathrm{P}<0.001), \mathrm{DM}$ (46.9\% vs. $46.6 \%, \mathrm{P}=0.724)$, and liver disease $(20.5 \%$ vs. $12.7 \%, \mathrm{P}<0.001)$; however, the difference in DM prevalence between patients with and without abnormal liver 


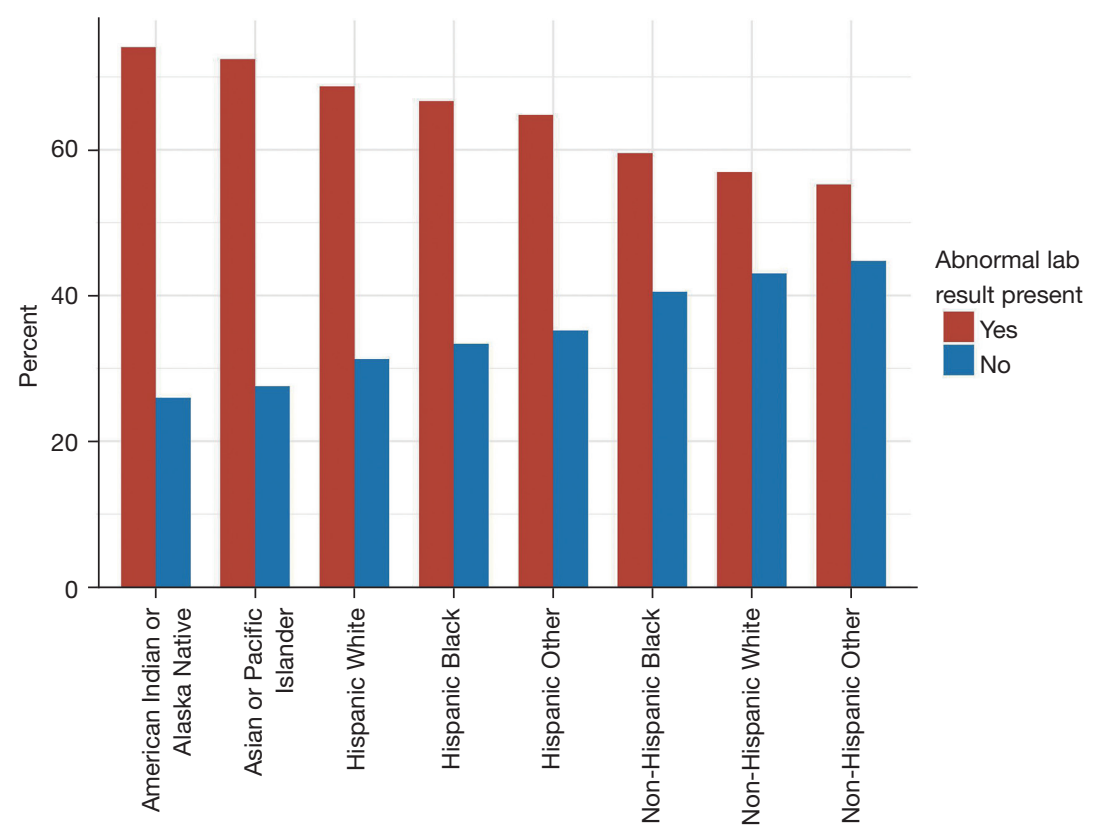

Figure 2 Patients with COVID-19. Race/ethnicity in patients with and without liver abnormalities. This histogram presents the proportion of patients in each racial/ethnic group who had and did not have at least one abnormality in liver chemistries. COVID-19, coronavirus disease 2019 .

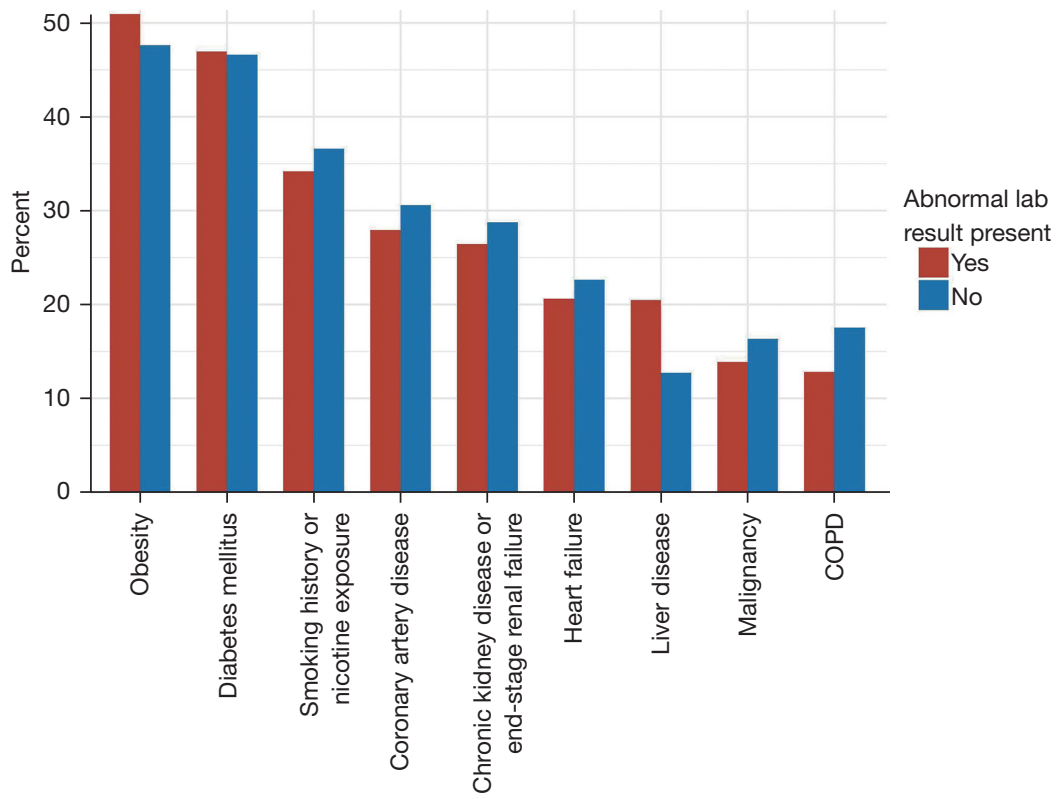

Figure 3 Patients with COVID-19. Comorbid conditions in patients with and without liver chemistry abnormalities. This histogram presents the proportion of patients with each comorbid condition who had and did not have at least one abnormality in liver chemistries. COPD, chronic obstructive pulmonary disease; COVID-19, coronavirus disease 2019. 


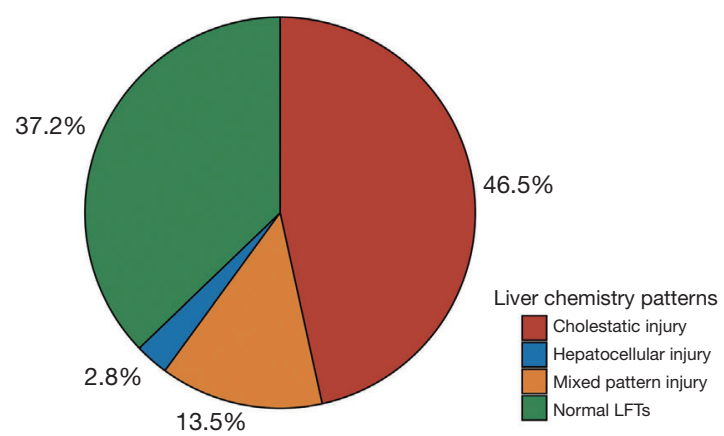

Figure 4 Liver chemistry patterns in patients with COVID-19. This chart presents the proportion of patients who had normal liver chemistries, as well as the patterns of liver injury present in patients with liver chemistry abnormalities. LFTs, liver function tests; COVID-19, coronavirus disease 2019.

chemistries was not significant. Mean albumin was slightly lower in the group with abnormal labs $(3.2$ vs. $3.4 \mathrm{mg} / \mathrm{dL}$, $\mathrm{P}<0.001)$. Prescriptions for $\mathrm{H} 2$ blockers were documented slightly more often in those with abnormal liver chemistries ( $0.7 \%$ vs. $0.6 \%, \mathrm{P}=0.686$ ), though the difference was not significant. PPIs were prescribed less frequently in those with abnormal liver chemistries ( $2.2 \%$ vs. $2.8 \%, \mathrm{P}=0.044)$.

The liver chemistries that were included in the analysis were ALT, AST, ALP and Tbili. A total of $37.2 \%(5,255 / 14,138)$ of patients had normal liver chemistries, and $62.8 \%(8,883 / 14,138)$ of patients had one or more abnormal chemistries, during the 24-hour before or after the documented start time of their COVID encounter. Among patients with abnormal liver chemistries $(\mathrm{n}=8,883)$, we calculated the $\mathrm{R}$ ratio and observed the cholestatic pattern in $74.1 \%$ of patients $(n=6,580)$, mixed in $21.5 \%$ of patients $(n=1,909)$ and hepatocellular in $4.4 \%$ of patients (n=394) (see Figure 4).

\section{Variables with known associations with prognosis}

Prior to conducting PS analysis, we used stepwise (bidirectional elimination) multiple logistic regression to analyze associations between gender, obesity, history of smoking or exposure to tobacco smoke, pre-existing liver disease, decreased albumin, and recent PPI use, and risk for death, intubation, and increased hospital LOS (see Table 2). These factors have been identified in previous studies as having significant associations with adverse patient outcomes in COVID-19 infection.

Mortality was significantly associated with male gender [adjusted relative risk (ARR), 1.45; 95\% CI: 1.35-1.55;
$\mathrm{P}<0.001$ ], obesity (ARR, 0.92; 95\% CI: 0.85-0.99; $\mathrm{P}=0.033$ ), pre-existing liver disease (ARR, 1.41; 95\% CI: 1.29-1.53; $\mathrm{P}<0.001)$, decreased serum albumin (ARR, 1.96; 95\% CI $1.83-2.10 ; \mathrm{P}<0.001)$ and PPI use (ARR, $1.41 ; 95 \% \mathrm{CI}$ : $1.16-1.71 ; \mathrm{P}=0.001)$.

Intubation was significantly associated with male gender (ARR, 1.57; 95\% CI: 1.47-1.68; $\mathrm{P}<0.001$ ), obesity (ARR, 1.24; 95\% CI: $1.15-1.33$; $\mathrm{P}<0.001)$, history of smoking or exposure to tobacco smoke (ARR, 0.90; 95\% CI: 0.83-0.98; $\mathrm{P}=0.010$ ), pre-existing liver disease (ARR 1.39; 95\% CI: 1.27-1.51; $\mathrm{P}<0.001$ ), and decreased serum albumin (ARR 1.73; 95\% CI: $1.60-1.85 ; \mathrm{P}<0.001)$. Hospital LOS $>3$ days was significantly associated with male gender (ARR, 1.13; 95\% CI: 1.12-1.15; $\mathrm{P}<0.001$ ), obesity (ARR, $1.03 ; 95 \%$ CI: 1.01-1.05; $\mathrm{P}=0.003$ ), pre-existing liver disease (ARR, 1.04; 95\% CI: 1.01-1.07; $\mathrm{P}=0.003)$, and decreased serum albumin (ARR, 1.21; 95\% CI: $1.20-1.22 ; \mathrm{P}<0.001)$.

\section{Propensity score analysis}

The full matching algorithm matched 8,879 (out of 8,883 ) individuals with abnormal liver chemistries with all 5,255 individuals who had only normal liver chemistries. In the matched cohort, the standardized differences in the covariates were all $<0.06$, indicating robust matching (9) (see Table S7). After matching, we used weighted logistic regression to analyze the impact of abnormalities in liver chemistries on the risk of death, intubation, and prolonged hospital LOS in patients with and without abnormalities in liver chemistries. Holding all other predictors fixed, the estimated risk of death was $70 \%$ higher for patients with at least one abnormal liver chemistry (ARR, 1.70; 95\% CI: $1.58-1.82$; $\mathrm{P}<0.001$; see Table 3); and estimated risk of intubation was $44 \%$ higher for these patients (ARR, 1.44; 95\% CI: 1.33-1.54; $\mathrm{P}<0.001$; see Table 3). Estimated risk of hospital LOS $>3$ days was also slightly increased for patients with at least one abnormal liver chemistry (ARR, 1.08; 95\% CI: 1.06-1.10; $\mathrm{P}<0.001$; see Table 3).

Treatment effect models were analyzed for sensitivity to hidden, or unmeasured, covariates via Rosenbaum's sensitivity tests. Sensitivity analyses demonstrated that the findings pertaining to the outcomes of mortality and intubation were highly robust to hidden bias from unmeasured covariates. The treatment effect estimates for the outcomes of death and intubation were both robust to hidden bias up to $\Gamma=11$. For hospital LOS, the treatment effect became insignificant at $\Gamma=1$, indicating that the finding pertaining to hospital LOS was not robust to hidden 
Table 2 Associations (relative risk) between gender, obesity, smoking or tobacco exposure, pre-existing liver disease, decreased albumin, and clinical outcomes (death, intubation, and increased length of stay) at the COVID-19 encounter

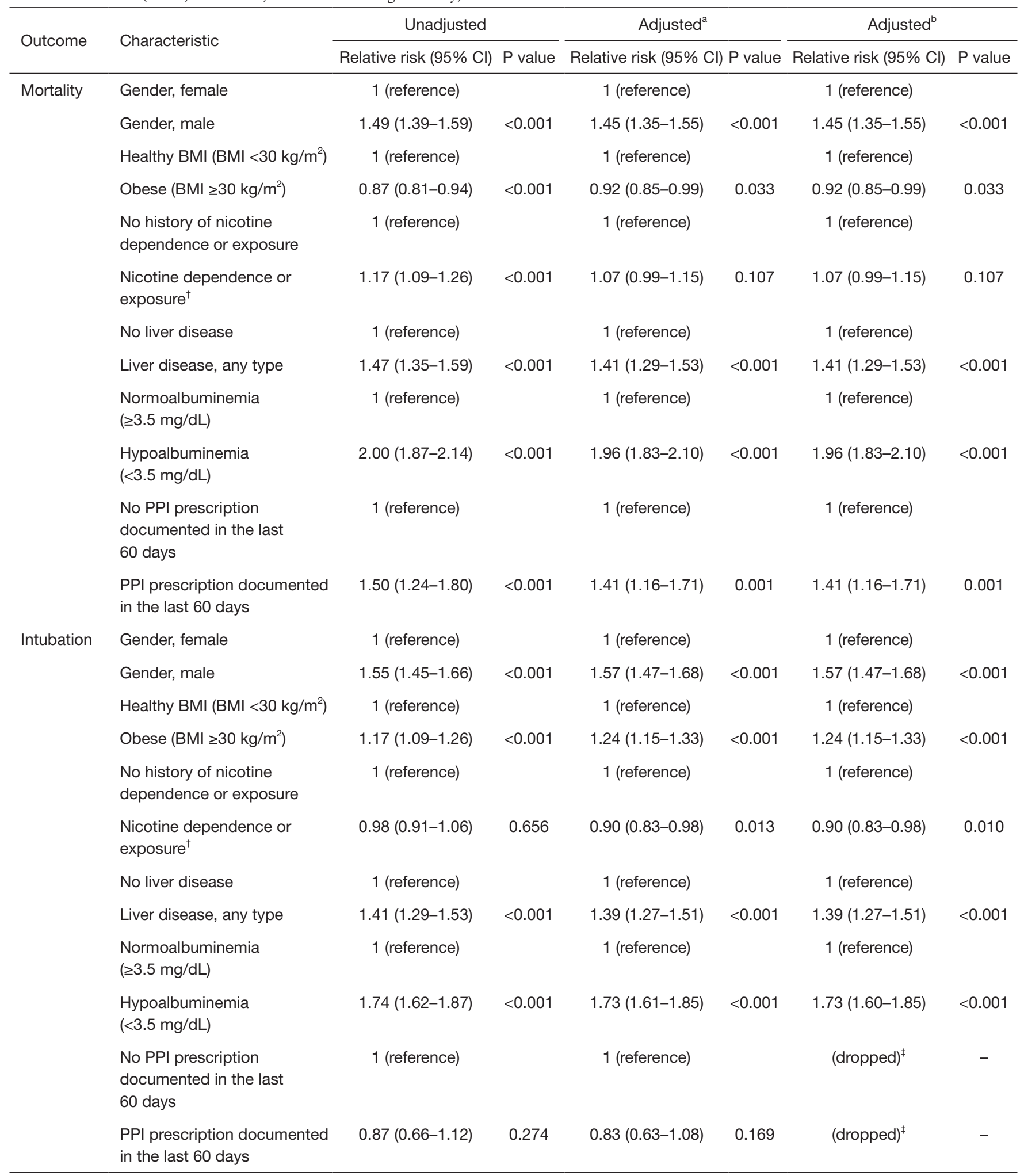

Table 2 (continued) 
Table 2 (continued)

\begin{tabular}{|c|c|c|c|c|c|c|c|}
\hline Outcome & Characteristic & \multicolumn{2}{|l|}{ Unadjusted } & \multicolumn{2}{|l|}{ Adjusted $^{\mathrm{a}}$} & \multicolumn{2}{|l|}{ Adjusted $^{b}$} \\
\hline \multirow{9}{*}{$\begin{array}{l}\text { LOS } \\
>3 \text { days }\end{array}$} & Gender, female & 1 (reference) & & 1 (reference) & & 1 (reference) & \\
\hline & Gender, male & $1.13(1.12-1.15)$ & $<0.001$ & $1.13(1.12-1.15)$ & $<0.001$ & $1.13(1.12-1.15)$ & $<0.001$ \\
\hline & Healthy BMI $\left(\mathrm{BMI}<30 \mathrm{~kg} / \mathrm{m}^{2}\right)$ & 1 (reference) & & 1 (reference) & & 1 (reference) & \\
\hline & $\begin{array}{l}\text { No history of nicotine } \\
\text { dependence or exposure }\end{array}$ & 1 (reference) & & 1 (reference) & & $(\text { dropped })^{\ddagger}$ & - \\
\hline & $\begin{array}{l}\text { Nicotine dependence or } \\
\text { exposure }^{\dagger}\end{array}$ & $1.02(1.00-1.04)$ & 0.028 & $1.00(0.98-1.03)$ & 0.729 & (dropped) $^{\ddagger}$ & - \\
\hline & No liver disease & 1 (reference) & & 1 (reference) & & 1 (reference) & \\
\hline & $\begin{array}{l}\text { Hypoalbuminemia } \\
(<3.5 \mathrm{mg} / \mathrm{dL})\end{array}$ & $1.21(1.20-1.22)$ & $<0.001$ & $1.21(1.20-1.22)$ & $<0.001$ & $1.21(1.20-1.22)$ & $<0.001$ \\
\hline & $\begin{array}{l}\text { No PPI prescription } \\
\text { documented in the last } \\
60 \text { days }\end{array}$ & 1 (reference) & & 1 (reference) & & $(\text { dropped })^{\ddagger}$ & - \\
\hline & $\begin{array}{l}\text { PPI prescription documented } \\
\text { in the last } 60 \text { days }\end{array}$ & $0.98(0.91-1.05)$ & 0.603 & $0.96(0.88-1.03)$ & 0.242 & $(\text { dropped })^{\ddagger}$ & - \\
\hline
\end{tabular}

${ }^{a}$, Logistic regression without variable selection; ${ }^{b}$, Stepwise (bidirectional elimination) logistic regression; ${ }^{\dagger}$, refers to current use or past history of dependency on nicotine products and/or documented exposure to environmental tobacco smoke; ${ }^{\ddagger}$, term was dropped from stepwise logistic regression model results. BMI, body mass index; $\mathrm{Cl}$, confidence interval; $\mathrm{kg} / \mathrm{m}^{2}$, kilograms per meter squared; LOS, length of stay; $\mathrm{mg} / \mathrm{dL}$, milligrams per deciliter; PPI, proton pump inhibitor.

Table 3 Propensity score-matched cohort: associations (relative risk) between demographic and clinical characteristics and clinical outcomes (death, intubation, and increased length of stay) at the COVID-19 encounter

\begin{tabular}{|c|c|c|c|c|c|c|c|}
\hline Outcome & Characteristic & \multicolumn{2}{|l|}{ Unadjusted } & \multicolumn{2}{|l|}{ Adjusted $^{a}$} & \multicolumn{2}{|l|}{ Adjusted $^{b}$} \\
\hline \multirow[t]{5}{*}{ Mortality } & $\mathrm{Age}^{\dagger}$ & $1.04(1.04-1.04)$ & $<0.001$ & $1.04(1.04-1.04)$ & $<0.001$ & $1.04(1.04-1.04)$ & $<0.001$ \\
\hline & Gender, female & 1 (reference) & & 1 (reference) & & 1 (reference) & \\
\hline & Gender, male & $1.45(1.35-1.55)$ & $<0.001$ & $1.44(1.34-1.55)$ & $<0.001$ & $1.44(1.34-1.55)$ & $<0.001$ \\
\hline & $\begin{array}{l}\text { Race/ethnicity, } \\
\text { non-Hispanic Black }\end{array}$ & $0.69(0.61-0.79)$ & $<0.001$ & $0.88(0.77-1.00)$ & 0.047 & $0.89(0.78-1.01)$ & 0.065 \\
\hline & $\begin{array}{l}\text { Race/ethnicity, AAPI/ } \\
\text { AIAN/non-Hispanic Other }\end{array}$ & $0.89(0.77-1.03)$ & 0.112 & $1.13(0.97-1.31)$ & 0.128 & $1.14(0.98-1.32)$ & 0.099 \\
\hline
\end{tabular}

Table 3 (continued) 
Table 3 (continued)

\begin{tabular}{|c|c|c|c|c|c|c|c|}
\hline Outcome & Characteristic & \multicolumn{2}{|l|}{ Unadjusted } & \multicolumn{2}{|l|}{ Adjusted $^{\mathrm{a}}$} & \multicolumn{2}{|l|}{ Adjusted $^{b}$} \\
\hline & Diabetes mellitus & $1.63(1.53-1.73)$ & $<0.001$ & $1.23(1.13-1.33)$ & $<0.001$ & $1.23(1.14-1.33)$ & $<0.001$ \\
\hline & $\begin{array}{l}\text { Chronic obstructive } \\
\text { pulmonary disease }\end{array}$ & $1.43(1.31-1.56)$ & $<0.001$ & $0.98(0.88-1.10)$ & 0.781 & $(\text { dropped })^{\S}$ & - \\
\hline & $\mathrm{BMI}^{\dagger}$ & $0.99(0.98-0.99)$ & $<0.001$ & $1.01(1.01-1.02)$ & $<0.001$ & $1.01(1.01-1.02)$ & $<0.001$ \\
\hline & $\begin{array}{l}\text { PPI prescription in the } \\
\text { last } 60 \text { days }\end{array}$ & $1.41(1.15-1.70)$ & 0.001 & $1.03(0.81-1.29)$ & 0.812 & $(\text { dropped })^{\S}$ & - \\
\hline & $\begin{array}{l}\mathrm{H} 2 \text { blocker prescription } \\
\text { in the last } 60 \text { days }\end{array}$ & 1.45 (0.98-2.03) & 0.059 & 1.09 (0.69-1.64) & 0.699 & $(\text { dropped })^{\S}$ & - \\
\hline & Blood type, O+ & 1 (reference) & & 1 (reference) & & (dropped) $^{\S}$ & - \\
\hline & Blood type, A+ & $0.96(0.88-1.05)$ & 0.362 & $0.93(0.85-1.02)$ & 0.107 & $(\text { dropped })^{\S}$ & - \\
\hline & Blood type, B+ & $0.94(0.83-1.06)$ & 0.326 & $1.00(0.88-1.14)$ & 0.978 & $(\text { dropped })^{\S}$ & - \\
\hline & Blood type, O- & $0.88(0.72-1.06)$ & 0.184 & $0.88(0.71-1.08)$ & 0.234 & $(\text { dropped })^{\S}$ & - \\
\hline & Blood type, A- & $1.04(0.85-1.27)$ & 0.681 & $0.92(0.73-1.14)$ & 0.458 & $(\text { dropped })^{\S}$ & - \\
\hline & Blood type, $\mathrm{AB}+$ & $1.04(0.82-1.30)$ & 0.769 & $1.04(0.80-1.32)$ & 0.781 & $(\text { dropped })^{\S}$ & - \\
\hline & Blood type, B- & $0.79(0.47-1.28)$ & 0.345 & $0.63(0.36-1.07)$ & 0.092 & $(\text { dropped })^{\S}$ & - \\
\hline & Blood type, AB- & $1.81(0.45-4.20)$ & 0.368 & $0.87(0.16-3.07)$ & 0.863 & $(\text { dropped })^{\S}$ & - \\
\hline & $\begin{array}{l}\text { Abnormal liver chemistry } \\
\text { result present }\end{array}$ & $1.51(1.40-1.62)$ & $<0.001$ & $1.70(1.58-1.83)$ & $<0.001$ & $1.70(1.58-1.82)$ & $<0.001$ \\
\hline \multirow[t]{7}{*}{ Intubation } & $\mathrm{Age}^{\dagger}$ & $1.01(1.01-1.01)$ & $<0.001$ & $1.01(1.01-1.01)$ & $<0.001$ & $1.01(1.01-1.01)$ & $<0.001$ \\
\hline & Gender, female & 1 (reference) & & 1 (reference) & & 1 (reference) & \\
\hline & Gender, male & $1.51(1.41-1.61)$ & $<0.001$ & $1.57(1.47-1.69)$ & $<0.001$ & $1.57(1.47-1.69)$ & $<0.001$ \\
\hline & $\begin{array}{l}\text { Race/ethnicity, } \\
\text { non-Hispanic White }\end{array}$ & 1 (reference) & & 1 (reference) & & 1 (reference) & \\
\hline & $\begin{array}{l}\text { Race/ethnicity, } \\
\text { non-Hispanic Black }\end{array}$ & $0.89(0.79-1.00)$ & 0.050 & $0.91(0.80-1.03)$ & 0.128 & $0.91(0.80-1.03)$ & 0.126 \\
\hline & $\begin{array}{l}\text { Race/ethnicity, AAPI/ } \\
\text { AIAN/non-Hispanic Other }\end{array}$ & $1.73(1.55-1.93)$ & $<0.001$ & $1.59(1.41-1.79)$ & $<0.001$ & $1.59(1.41-1.79)$ & $<0.001$ \\
\hline & Race/ethnicity, Hispanic & $1.04(0.96-1.13)$ & 0.360 & $0.94(0.85-1.03)$ & 0.185 & $0.94(0.85-1.03)$ & 0.177 \\
\hline
\end{tabular}

Table 3 (continued) 
Table 3 (continued)

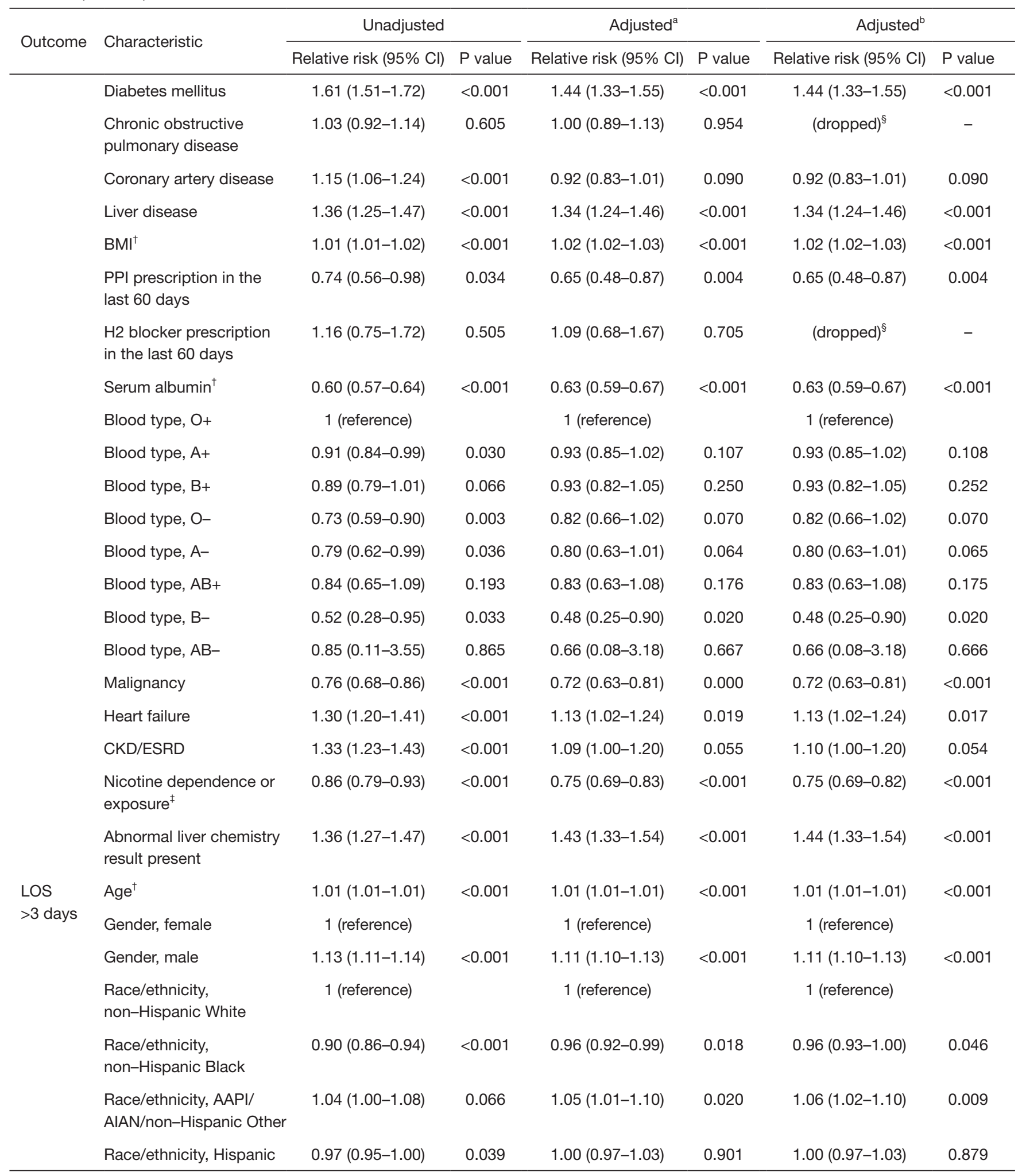

Table 3 (continued) 
Table 3 (continued)

\begin{tabular}{|c|c|c|c|c|c|c|c|}
\hline Outcome & Characteristic & \multicolumn{2}{|l|}{ Unadjusted } & \multicolumn{2}{|l|}{ Adjusted $^{\mathrm{a}}$} & \multicolumn{2}{|l|}{ Adjusted $^{\mathrm{b}}$} \\
\hline & Diabetes mellitus & $1.17(1.16-1.18)$ & $<0.001$ & $1.10(1.08-1.12)$ & $<0.001$ & $1.10(1.08-1.12)$ & $<0.001$ \\
\hline & $\begin{array}{l}\text { Chronic obstructive } \\
\text { pulmonary disease }\end{array}$ & $1.07(1.04-1.10)$ & $<0.001$ & $0.97(0.93-1.01)$ & 0.208 & $0.97(0.93-1.01)$ & 0.192 \\
\hline & $\mathrm{BMI}^{\dagger}$ & $1.00(1.00-1.00)$ & 0.025 & $1.01(1.00-1.01)$ & $<0.001$ & $1.01(1.00-1.01)$ & $<0.001$ \\
\hline & $\begin{array}{l}\text { PPI prescription in the } \\
\text { last } 60 \text { days }\end{array}$ & $0.93(0.85-0.99)$ & 0.034 & $0.81(0.73-0.90)$ & $<0.001$ & $0.81(0.73-0.90)$ & $<0.001$ \\
\hline & $\begin{array}{l}\mathrm{H} 2 \text { blocker prescription } \\
\text { in the last } 60 \text { days }\end{array}$ & $0.97(0.82-1.09)$ & 0.631 & $0.92(0.75-1.06)$ & 0.312 & (dropped) $^{\S}$ & - \\
\hline & Blood type, O+ & 1 (reference) & & 1 (reference) & & (dropped) $^{\S}$ & - \\
\hline & Blood type, $A_{+}$ & $0.99(0.97-1.02)$ & 0.616 & $0.99(0.97-1.02)$ & 0.672 & (dropped) $^{\S}$ & - \\
\hline & Blood type, B+ & $0.99(0.95-1.02)$ & 0.458 & $1.02(0.98-1.06)$ & 0.279 & (dropped) $^{\S}$ & - \\
\hline & Blood type, O- & $0.91(0.85-0.97)$ & 0.001 & $0.92(0.86-0.98)$ & 0.009 & $(\text { dropped })^{\S}$ & - \\
\hline & Blood type, A- & $1.00(0.94-1.06)$ & 0.920 & $0.98(0.91-1.04)$ & 0.579 & $(\text { dropped) })^{\S}$ & - \\
\hline & Blood type, $\mathrm{AB}+$ & $1.05(0.98-1.11)$ & 0.193 & $1.04(0.97-1.11)$ & 0.256 & (dropped) $^{\S}$ & - \\
\hline & Blood type, B- & $0.97(0.82-1.09)$ & 0.616 & $0.94(0.78-1.07)$ & 0.391 & (dropped) $)^{\S}$ & - \\
\hline & Blood type, AB- & $1.38(0.00-1.38)$ & 0.929 & $1.38(0.00-1.38)$ & 0.931 & $(\text { dropped })^{\S}$ & - \\
\hline & $\begin{array}{l}\text { Abnormal liver chemistry } \\
\text { result present }\end{array}$ & $1.07(1.05-1.09)$ & $<0.001$ & $1.08(1.06-1.10)$ & $<0.001$ & $1.08(1.06-1.10)$ & $<0.001$ \\
\hline
\end{tabular}

a , Logistic regression without variable selection; ${ }^{b}$, Stepwise (bidirectional elimination) logistic regression; ${ }^{\dagger}$, analyzed as a continuous variable. Odds ratio interpretations: (I) a one-unit change in age is equivalent to a change of 1 year, (II) a one-unit change in BMI is equivalent to a change of $1 \mathrm{~kg} / \mathrm{m}^{2}$, and (III) a one-unit change in serum albumin is equivalent to a change of $1 \mathrm{mg} / \mathrm{dL}$; ${ }^{\ddagger}$, refers to current use or past history of dependency on nicotine products and/or documented exposure to environmental tobacco smoke; ${ }^{\S}$, term was dropped from stepwise logistic regression model results. AAPI, Asian American or Pacific Islander; AIAN, American Indian or Alaska Native; BMI, body mass index; $\mathrm{Cl}$, confidence interval; CKD/ESRD, Chronic kidney disease/End-stage renal disease; $\mathrm{H} 2$ blocker, histamine 2 receptor agonist; LOS, length of stay; PPI, proton pump inhibitor.

bias from unmeasured covariates.

\section{Effect of presence of liver injury}

To further examine the impact of specific liver chemistry derangements on patient outcomes and to identify the abnormalities associated with the highest risk for poor outcomes, we used three stepwise (bidirectional elimination) multiple logistic regression models to analyze whether abnormalities in ALT, AST, ALP, and total bilirubin were 
Table 4 Associations (relative risk) between elevated liver chemistries and clinical outcomes (death, intubation, and increased length of stay) at the COVID-19 encounter

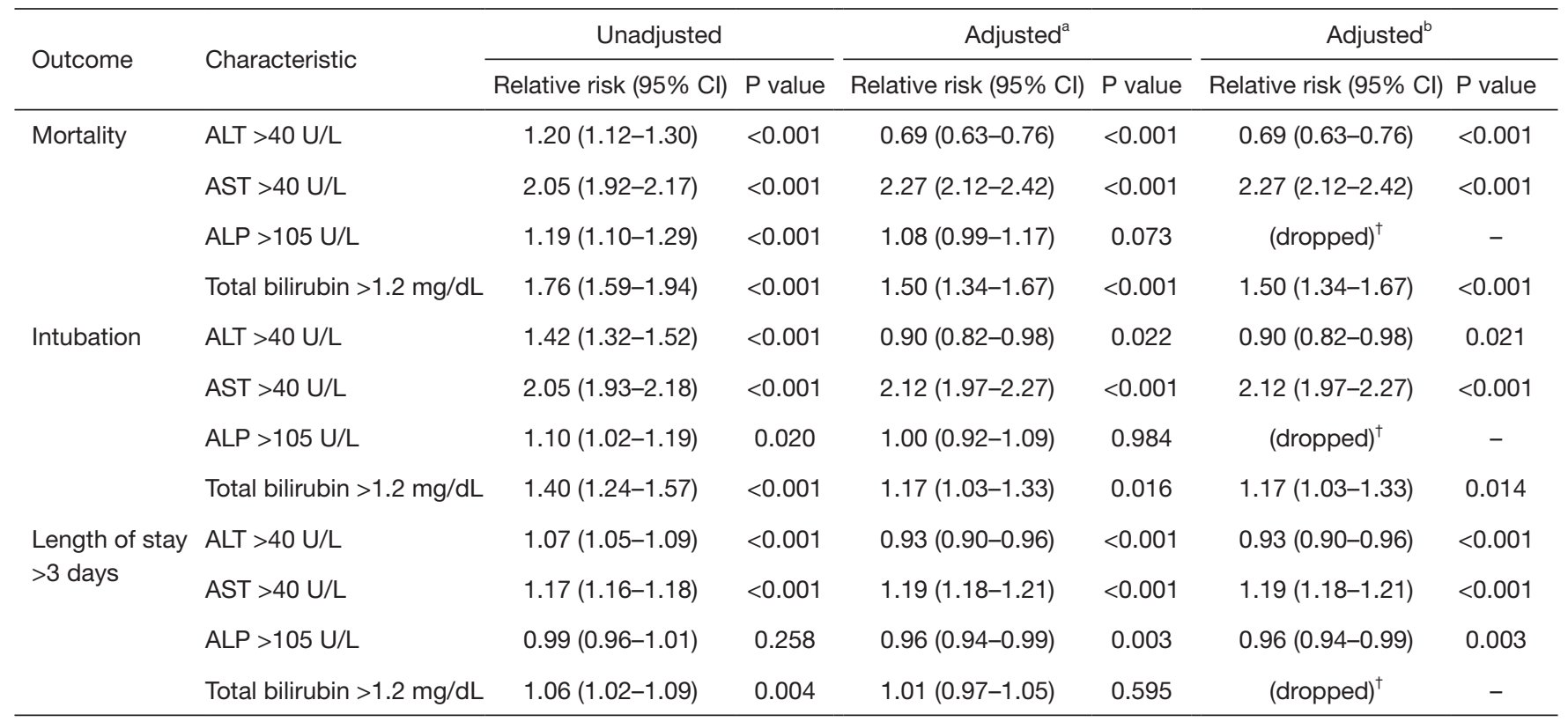

${ }^{a}$, Logistic regression without variable selection; ${ }^{b}$, Stepwise (bidirectional elimination) logistic regression; ${ }^{\dagger}$, term was dropped from stepwise logistic regression model results. ALP, alkaline phosphatase; ALT, alanine aminotransferase; AST, aspartate aminotransferase; CI, confidence interval; $\mathrm{mg} / \mathrm{dL}$, milligrams per deciliter; $\mathrm{U} / \mathrm{L}$, units per liter.

associated with increased risk of death, intubation, and increased hospital LOS (see Table 3). These models, which adjusted only for elevations in the four liver chemistries, used the following thresholds to define abnormalities for these parameters: ALP >105 U/L, AST >40 U/L, ALT $>40 \mathrm{U} / \mathrm{L}$, and Tbili $>1.2 \mathrm{mg} / \mathrm{dL}(6,7)$. Mortality was significantly associated with derangements in ALT (ARR, 0.69; 95\% CI: 0.63-0.76; $\mathrm{P}<0.001$ ), AST (ARR, 2.27; 95\% CI: 2.12-2.42; $\mathrm{P}<0.001$ ), and Tbili (ARR, 1.50; 95\% CI: $1.34-1.67 ; \mathrm{P}<0.001)$. Risk for intubation was significantly associated with derangements in ALT (ARR, 0.90; 95\% CI: 0.82-0.98; $\mathrm{P}=0.021$ ), AST (ARR, 2.12; 95\% CI: 1.97-2.27; $\mathrm{P}<0.001$ ), and Tbili (ARR, 1.17; 95\% CI: 1.03-1.33; $\mathrm{P}=0.014)$. Hospital LOS $>3$ days was significantly associated with abnormalities in ALT (ARR, 0.93; 95\% CI: 0.90-0.96; $\mathrm{P}<0.001$ ), AST (ARR, 1.19; 95\% CI: 1.18-1.21; $\mathrm{P}<0.001$ ), and ALP (ARR, 0.96; 95\% CI: 0.94-0.99; $\mathrm{P}=0.003$ ). These findings are outlined in Table 4.

\section{Discussion}

Coronavirus-19 infection can affect numerous organs including the liver. The hepatotoxic effect is thought to be predominantly mediated by its interaction with the angiotensin-converting enzyme 2 (ACE2) receptor in the liver, especially on the cholangiocytes manifesting as intrahepatic cholestasis (11). Microvesicular steatosis and portal inflammation has been seen on autopsies of patients with the infection (12). Other possible mechanisms of hepatotoxicity include direct damage to the hepatocytes causing viral hepatitis and indirect damage may occur secondary to systemic immune mediated response or from medications that may be used for treatment of the infection itself (13). The degree of hepatic inflammation and injury can vary from being mild to severe and potentially acute fulminant liver injury can occur.

Male gender has been associated with an increased risk of hepatic damage $(14,15)$. In our study, $53.1 \%$ of those with abnormalities in liver chemistries were male. Male gender was also associated with increased risk of mortality (RR 1.45), intubation (RR 1.57), and prolonged hospitalization (RR 1.13). This suggests that males may be at a higher risk for COVID-19 related liver injury; however, further evaluation is necessary to define this association.

Obesity has been linked with adverse outcomes, including increased mortality (16). It impairs the cytotoxic cellular response to viral infections by modifying the reaction of cytokines and through its effects on hormones like leptin (17). 
Our study indicates that obesity increases risk for intubation (RR 1.24) and prolonged hospitalization (RR 1.03). Interestingly, obesity was associated with a slightly decreased risk for mortality (RR 0.92). While the reason for this decreased mortality risk is not fully clear, it is possible that, in this patient population, obesity may impact mortality risk through interactions with other patient factors.

Smoking is another factor to consider in patients with SARS-CoV-2 infection and is associated with worse outcomes in some studies and an unexpectedly beneficial effect in others. An increased expression of the ACE2 gene in the lungs and a higher number of ACE2-producing goblet cells was found in those who have ever smoked as compared to those who have never smoked in a study performed by Cai et al. (18). A large study based in Iran saw that cigarette smoking was associated with an increased risk of mortality related to COVID-19 though a negative correlation with hospitalization (19). Another study that was carried out in Wuhan found that history of smoking was linked to progression of disease (20). Conflicting data was noted by Lippi et al. in their meta-analysis on Chinese patients that revealed active smoking was not linked to a higher risk for progression of severe disease in cases of SARS-CoV-2 infection (21). Several studies have revealed a potentially beneficial effect of smoking and this may be due to possible confounding variables (22). In our model that adjusted for gender, obesity, smoking history, presence of chronic liver disease, decreased albumin and PPI use, the association between smoking and mortality was not significant. However, smoking was linked to a reduced risk for intubation (RR 0.90). Hence further studies are needed to analyze the effects of smoking on the course of SARS$\mathrm{CoV}-2$ infection.

The presence of pre-existing liver disease was also associated with an increased relative risk of mortality (RR 1.41), intubation (RR 1.39) and prolonged hospital LOS (RR 1.04). This is an important comorbid condition to recognize due to its negative impact on infection outcomes.

Hypoalbuminemia was also associated with increased relative risk for mortality (RR 1.96), intubation (1.73), and prolonged hospitalization (RR 1.21). Serum albumin levels were lower in patients with abnormal chemistries. Low albumin levels have been shown in several studies to be linked to a more severe phenotypic presentation of COVID-19 infection (23-25). Hypoalbuminemia has also been shown to correlate with a poor prognosis including a higher probability of respiratory decompensation with need for respiratory support (20).
Recent use of PPIs (within 60 days of admission) was linked to increased relative risk of mortality (RR 1.41). This association has been reported in many other studies, with PPIs being linked to worse outcomes and increased mortality (26-28). PPI therapy causes hypochlorhydria with suppression of the effect of the gastric acid, hence promoting the survival of the virus and the resultant virulent effects $(27,28)$. Hypochlorhydria also increases the bacterial load in the stomach and can lead to small intestinal bacterial overgrowth $(27,28)$. In cases of micro-aspiration, the bacteria from the stomach can cause a secondary infection in the lungs and augment the chances of developing Acute Respiratory Distress Syndrome and worse outcomes including increased mortality $(27,28)$. Indirect inhibition of nitric oxide synthase leads to thrombosis and inflammation with negative cardiovascular effects $(27,28)$. They also exert a negative impact on neutrophil function and hence impair the immune response to the virus $(27,29)$. In our stepwise models, PPI use was not associated with higher risk for intubation or prolonged hospitalization.

Small studies have revealed that there is an association between liver injury and worse outcomes and prognosis $(7,11,13,30)$. To the best of our knowledge, this is the largest study to evaluate associations between elevated liver chemistries on admission and the outcomes of mortality, intubation, and duration of hospitalization. Propensity score analysis indicated that the relative risk of mortality was 1.70 times higher, and the relative risk of intubation was 1.44 times higher, in those with abnormal liver chemistries. Risk for prolonged hospitalization was also 1.08 times higher in this patient cohort, though this finding was highly sensitive to unmeasured covariates.

The study conducted by Medetalibeyoglu et al., with 554 subjects, they found that patients with a high ALT-AST ratio during their hospitalization had increased mortality and requirement for ICU level of care (7). They noted that AST/ALT ratio $>1$ led to worse outcomes including higher mortality (7). Lei et al. reviewed 5,771 patients in a multicenter retrospective study and evaluated levels of AST, ALP, ALT and total bilirubin during the course of their hospitalization (31). It showed that initially AST increased then the ALT in severe cases and the ALP increase was noted to be modest with mild fluctuations in total bilirubin (31). Hence they concluded that the AST elevations were linked to the highest mortality (31). A prospective study that consisted of 217 patients showed that increase in ALT, GGT (gamma-glutamyl transferase) and low albumin levels on hospital admission were all linked to severe infection 
and unfavorable outcomes such ICU stay and mechanical ventilation (32).

Similarly, in our study, we saw that derangements in liver chemistries on admission were associated with patient outcomes. In models that adjusted for elevations in all four chemistries, elevation in AST was associated with the highest risks for mortality, intubation, and prolonged hospitalization. In the same adjusted models, ALT elevation was associated with a decreased relative risk for mortality, intubation, and prolonged hospitalization. Elevated ALP was linked to decreased risk for prolonged hospitalization. Elevation in total bilirubin was associated with increased risks for mortality and intubation. Based on the calculation of the $\mathrm{R}$ ratio, the predominant pattern of liver enzyme elevation seen is this study was the cholestatic pattern.

A meta-analysis that included sixty-four studies showed that in severe cases of COVID-19 infection, the prevalence of an increased AST level was significantly higher (33). The worldwide prevalence of an increased AST was also higher as compared to ALT, ALP, total bilirubin and gammaglutamyltransferase (33). Another large study conducted in China showed that $39.4 \%$ of patients had an AST value $>40 \mathrm{U} / \mathrm{L}$ and $28.1 \%$ had ALT $>40 \mathrm{U} / \mathrm{L}$ and these elevations were found more commonly in those with severe disease (30). Slightly different findings were portrayed in another metaanalysis with ALT and bilirubin levels being significantly increased and serum albumin levels being significantly decreased in those with severe infection (23). Hence though the data thus far shows that elevation in AST tends to occur more frequently and is more profound in those with severe disease, this finding needs further investigation.

As further data emerge and our understanding of the virus evolves, there will be additional clarity with regards to hepatic involvement secondary to COVID-19 infection and outcomes. Understanding the patient profile and baseline comorbid conditions is important as they impact the clinical course and are linked to severity of infection. Of all the liver chemistries, elevated AST was associated with the greatest risk for negative outcomes. However, the source of AST in the body is not solely the liver and the AST elevation can be driven potentially from muscle injury as well. The liver injury can occur from other hepatotoxic agents such as medications that are used in the treatment for the virus or other medications used during hospitalization. These factors need to be considered when evaluating patients with liver injury. A routine liver panel is obtained during admission for most hospitalized patients. If abnormalities are detected, patients should be monitored closely to follow the trend.

\section{Limitations and strengths}

The retrospective design of our study is a significant limitation. We also did not account for elevations in liver chemistries that occurred more than 24 hours after the start time of the COVID encounter. Further study is needed to analyze the impact of derangements in liver chemistries that occur more than 24 hours after admission. We also chose to exclude patients who had missing data for any of the covariates or outcomes analyzed in this study. A major strength of our study is its large, geographically diverse sample of patients with laboratory-confirmed COVID-19 infection. To address limitations inherent in retrospective cohort analysis, we used propensity score analysis to reduce confounding due to imbalance in observed covariates.

\section{Conclusions}

Using a large, nationwide cohort that includes more than 14,000 patients with laboratory-confirmed COVID-19 infection, we observed that liver chemistry abnormalities at the time of admission impact risk for mortality, intubation, and prolonged hospital LOS. The greatest risk for all three adverse outcomes is associated with elevated AST. A liver chemistry panel should be obtained with routine laboratory tests when patients test positive for COVID-19 infection. These results should be used for risk stratification. Clinicians should be cautious when derangements in liver chemistries are noted on presentation as they could be harbingers of eventual decompensation. Further studies are needed to develop more precise prediction models and scoring systems.

\section{Acknowledgments}

Funding: EMT is supported by the National Institutes of Health (No. 5T32LM012410). The content is solely the responsibility of the authors and does not necessarily represent the official views of the NIH.

\section{Footnote}

Reporting Checklist: The authors have completed the STROBE reporting checklist. Available at https://tgh. amegroups.com/article/view/10.21037/tgh-21-94/rc

Data Sharing Statement: Available at https://tgh.amegroups. 
com/article/view/10.21037/tgh-21-94/dss

Peer Review File: Available at https://tgh.amegroups.com/ article/view/10.21037/tgh-21-94/prf

Conflicts of Interest: All authors have completed the ICMJE uniform disclosure form (available at https://tgh.amegroups. com/article/view/10.21037/tgh-21-94/coif). The authors have no conflicts of interest to declare.

Ethical Statement: The authors are accountable for all aspects of the work in ensuring that questions related to the accuracy or integrity of any part of the work are appropriately investigated and resolved. The study was conducted in accordance with the Declaration of Helsinki (as revised in 2013). The University of Missouri Institutional Review Board (Federalwide Assurance ID: FWA00002876) deemed this study of de-identified patient data to not constitute human subjects research; therefore, direct informed consent from individual patients was not required (IRB \#2034442).

Open Access Statement: This is an Open Access article distributed in accordance with the Creative Commons Attribution-NonCommercial-NoDerivs 4.0 International License (CC BY-NC-ND 4.0), which permits the noncommercial replication and distribution of the article with the strict proviso that no changes or edits are made and the original work is properly cited (including links to both the formal publication through the relevant DOI and the license). See: https://creativecommons.org/licenses/by-nc-nd/4.0/.

\section{References}

1. Baloch S, Baloch MA, Zheng T, et al. The Coronavirus Disease 2019 (COVID-19) Pandemic. Tohoku J Exp Med 2020;250:271-8.

2. Gavriatopoulou M, Korompoki E, Fotiou D, et al. Organspecific manifestations of COVID-19 infection. Clin Exp Med 2020;20:493-506.

3. Polack FP, Thomas SJ, Kitchin N, et al. Safety and Efficacy of the BNT162b2 mRNA Covid-19 Vaccine. N Engl J Med 2020;383:2603-15.

4. Cerner Corporation. Cerner provides access to deidentified patient data for COVID-19 research and vaccine development (news release). 2020 Apr 24 (cited 2021 Sept 16). Available online: https://www.cerner.com/newsroom/ cerner-provides-access-to-de-identified-patient-data-for- covid-19-research-and-vaccine-development

5. Qureshi AI, Baskett WI, Huang W, et al. Facilitating the study of relationships between COVID-19 and cardiovascular health outcomes using Cerner RealWorld COVID-19 deidentified dataset. HealthCare Res J 2020;1:17-28.

6. European Association for the Study of the Liver. EASL Clinical Practice Guidelines: management of cholestatic liver diseases. J Hepatol 2009;51:237-67.

7. Medetalibeyoglu A, Catma Y, Senkal N, et al. The effect of liver test abnormalities on the prognosis of COVID-19. Ann Hepatol 2020;19:614-21.

8. Ehwerhemuepha L, Gasperino G, Bischoff N, et al. HealtheDataLab - a cloud computing solution for data science and advanced analytics in healthcare with application to predicting multi-center pediatric readmissions. BMC Med Inform Decis Mak 2020;20:115.

9. Lee J, Little TD. A practical guide to propensity score analysis for applied clinical research. Behav Res Ther 2017;98:76-90.

10. Austin PC. An Introduction to Propensity Score Methods for Reducing the Effects of Confounding in Observational Studies. Multivariate Behav Res 2011;46:399-424.

11. Zhang C, Shi L, Wang FS. Liver injury in COVID-19: management and challenges. Lancet Gastroenterol Hepatol 2020;5:428-30.

12. Xu Z, Shi L, Wang Y, et al. Pathological findings of COVID-19 associated with acute respiratory distress syndrome. Lancet Respir Med 2020;8:420-2.

13. Gu J, Han B, Wang J. COVID-19: Gastrointestinal Manifestations and Potential Fecal-Oral Transmission. Gastroenterology 2020;158:1518-9.

14. Zhang H, Liao YS, Gong J, et al. Clinical characteristics and risk factors for liver injury in COVID-19 patients in Wuhan. World J Gastroenterol 2020;26:4694-702.

15. Xie H, Zhao J, Lian N, et al. Clinical characteristics of non-ICU hospitalized patients with coronavirus disease 2019 and liver injury: A retrospective study. Liver Int 2020;40:1321-6.

16. Tartof SY, Qian L, Hong V, et al. Obesity and Mortality Among Patients Diagnosed With COVID-19: Results From an Integrated Health Care Organization. Ann Intern Med 2020;173:773-81.

17. Rojas-Osornio SA, Cruz-Hernández TR, Drago-Serrano $\mathrm{ME}$, et al. Immunity to influenza: Impact of obesity. Obes Res Clin Pract 2019;13:419-29.

18. Cai G, Bossé Y, Xiao F, et al. Tobacco Smoking Increases the Lung Gene Expression of ACE2, the 
Receptor of SARS-CoV-2. Am J Respir Crit Care Med 2020;201:1557-9.

19. Khorrami Z, Nili S, Sharifi H, et al. Association of cigarette smoking, obesity, and underlying medical conditions with COVID-19 hospitalization and mortality in Iran: A nationwide retrospective ecological study. Med J Islam Repub Iran 2020;34:133.

20. Liu W, Tao ZW, Wang L, et al. Analysis of factors associated with disease outcomes in hospitalized patients with 2019 novel coronavirus disease. Chin Med J (Engl) 2020;133:1032-8.

21. Lippi G, Sanchis-Gomar F, Henry BM. Active smoking and COVID-19: a double-edged sword. Eur J Intern Med 2020;77:123-4.

22. Wenzl T. Smoking and COVID-19 - A review of studies suggesting a protective effect of smoking against COVID-19, EUR 30373 EN, Publications Office of the European Union, Luxembourg, 2020, ISBN 97892-76-22062-6 (online), doi:10.2760/564217 (online), JRC121837.

23. Ahmed J, Rizwan T, Malik F, et al. COVID-19 and Liver Injury: A Systematic Review and Meta-Analysis. Cureus 2020;12:e9424.

24. Aziz M, Fatima R, Lee-Smith W, et al. The association of low serum albumin level with severe COVID-19: a systematic review and meta-analysis. Crit Care 2020;24:255.

25. Chen G, Wu D, Guo W, et al. Clinical and immunological features of severe and moderate coronavirus disease 2019.

doi: $10.21037 / \operatorname{tgh}-21-94$

Cite this article as: Chela HK, Tallon EM, Baskett W, Gangu K, Tahan V, Shyu CR, Daglilar E. Liver injury on admission linked to worse outcomes in COVID-19: an analysis of 14,138 patients. Transl Gastroenterol Hepatol 2023;8:4.
J Clin Invest 2020;130:2620-9.

26. Lee SW, Ha EK, Yeniova AÖ, et al. Severe clinical outcomes of COVID-19 associated with proton pump inhibitors: a nationwide cohort study with propensity score matching. Gut 2021;70:76-84.

27. Hariyanto TI, Prasetya IB, Kurniawan A. Proton pump inhibitor use is associated with increased risk of severity and mortality from coronavirus disease 2019 (COVID-19) infection. Dig Liver Dis 2020;52:1410-2.

28. Corsonello A, Lattanzio F, Bustacchini S, et al. Adverse Events of Proton Pump Inhibitors: Potential Mechanisms. Curr Drug Metab 2018;19:142-54.

29. Namazi MR, Jowkar F. A succinct review of the general and immunological pharmacologic effects of proton pump inhibitors. J Clin Pharm Ther 2008;33:215-7.

30. Guan WJ, Ni ZY, Hu Y, et al. Clinical Characteristics of Coronavirus Disease 2019 in China. N Engl J Med 2020;382:1708-20.

31. Lei F, Liu YM, Zhou F, et al. Longitudinal Association Between Markers of Liver Injury and Mortality in COVID-19 in China. Hepatology 2020;72:389-98.

32. Weber S, Hellmuth JC, Scherer C, et al. Liver function test abnormalities at hospital admission are associated with severe course of SARS-CoV-2 infection: a prospective cohort study. Gut 2021;70:1925-32.

33. Wijarnpreecha K, Ungprasert P, Panjawatanan P, et al. COVID-19 and liver injury: a meta-analysis. Eur J Gastroenterol Hepatol 2021;33:990-5. 


\section{Supplementary}

Table S1 LOINC laboratory codes considered indicative of SARS-CoV-2 infection

\begin{tabular}{ll}
\hline LOINC code & Description \\
\hline $41458-1$ & SARS coronavirus RNA [Presence] in Unspecified specimen by NAA with probe detection \\
$94309-2$ & SARS coronavirus 2 RNA [Presence] in Unspecified specimen by NAA with probe detection \\
$94500-6$ & SARS coronavirus 2 RNA [Presence] in Respiratory specimen by NAA with probe detection \\
$94533-7$ & SARS coronavirus 2 N gene [Presence] in Respiratory specimen by NAA with probe detection \\
$94534-5$ & SARS coronavirus 2 RdRp gene [Presence] in Respiratory specimen by NAA with probe detection \\
$94646-7$ & SARS coronavirus 2 RdRp gene [Cycle Threshold \#] in Respiratory specimen by NAA with probe detection \\
\hline
\end{tabular}

These codes exclude antibody tests and older, ambiguous LOINC codes that may be less definitively consistent with true, unambiguous cases of SARS-CoV-2 infection. LOINC, Logical Observation Identifiers Names and Codes; NAA, nucleic acid amplification; RdRp, RNA (ribonucleic acid)-dependent RNA polymerase; RNA, ribonucleic acid; SARS, severe acute respiratory syndrome; SARS-CoV-2, SARS coronavirus 2 .

Table S2 LOINC laboratory codes for liver chemistries

\begin{tabular}{ll}
\hline Laboratory test & LOINC codes \\
\hline Alkaline phosphatase & $1783-0,6768-6$ \\
Aspartate aminotransferase & $1920-8,30239-8$ \\
Alanine aminotransferase & $1742-6,1743-4,1744-2$ \\
Total bilirubin & $1975-2,14631-6,42719-5$ \\
Albumin & $1751-7,2862-1,61151-7,61152-5$ \\
\hline
\end{tabular}

LOINC, Logical Observation Identifiers Names and Codes. 
Table S3 Comorbidity case definitions and codes

\begin{tabular}{lll}
\hline Variable & ICD-9-CM codes (X is a wildcard character) & ICD-10-CM codes (X is a wildcard character) \\
\hline Diabetes mellitus & 250.X, 357.2, 362.0X, 366.41 & $\begin{array}{l}\text { E08, E08.X, E09, E09.X, E10, E10.X, E11, E11.X, E13, E13. } \\
\text { X }\end{array}$ \\
$\begin{array}{l}\text { Chronic obstructive pulmonary } \\
\text { disease }\end{array}$ & $\begin{array}{l}491.20,491.21,491.22,493.20,493.21, \\
493.22,496\end{array}$ & J44.0, J44.1, J44.9
\end{tabular}

Coronary artery disease

Liver disease

Heart failure

Chronic kidney disease or end-stage renal failure tobacco smoke

Malignancy
410.01, 410.11, 410.21, 410.31, 410.41, $410.51,410.61,410.71,410.81,410.91,411.1$, $412,413.9,414.01,414.02,414.03,414.04$, 414.05, 414.06, 414.07, 414.10, 414.2, 414.3, $414.4,414.8,414.9,429.2,429.5,429.6$, 429.71, 429.79, V12.50, V12.50, V12.59, V45.82

070.0, 070.1, 070.20, 070.30, 070.31, 070.32, 070.41, 070.44, 070.54, 070.6, 070.7X, 070.9, 155.0, 155.2, 197.7, 211.5, 273.4, 275.01, 275.1, 570, 571.0, 571.1, 571.2, 571.3, 571.40, $571.41,571.42,571.49,571.5,571.6,571.8$, 571.9, 572.2, 572.3, 572.8, 573.0, 573.3, 573.8, $573.9,646.70,751.62, \mathrm{~V} 10.07, \mathrm{~V} 42.7$
I21, 121.X, I22, 122.X, 123, 123.X, 125, 125.1X, 125.2X, 125.5X, I25.6X, I25.7X, I25.8X, I25.9X, Z86.74, Z86.79, Z98.6, Z98.61,

K70X, K71.0, K71.10, K71.11, K71.2, K71.3, K71.51, K71.6, K71.7, K71.8, K71.9, K72X, K73X, K74X, K75.2, K75.3, K75.4, K75.81, K75.89, K75.9, K76.0, K76.1, K76.6, K76.89, K76.9, K77, K83.01, C7B.02, C22.0, C22.4, C22.7, C22.8, C22.9, B00.81, B15.9, B16.9, B17.10, B17.11, , B17.2, B17.8, B17.9, B18.0, B18.1, B18.2, B18.8, B18.9, B19X, B25.1, B94.2, E83.01, E83.110, E88.01, Z20.5, Z22.51, Z22.52, Z85.05, O26.611, O26.612, O26.613, O26.619, O26.62, O26.63, O98.411, O98.412, O98.413, 098.419, 098.41, 098.42, 098.43, Q44.6, Q44.7, T86.42, T86.43, V02.62, P78.81

History of nicotine dependence $305.1,649.00,649.01,649.02,649.03,649.04, \quad$ Z57.31, Z72.0, Z77.22, Z87.891, O99.33X, F17X or exposure to environmental $\quad \mathrm{V} 15.82$

V10X, 140X, 141X, 142X, 143X, 144X, 145X, 146X, 147X, 148X, 149X, 150X, 151X, 152X, 153X, 154X, 155X, 156X, 157X, 158X, 159X, 160X, 161X, 162X, 163X, 164X, 165X, 170X, 171X, 172X, 173X, 174X, 175X, 176X, 179X, 180X, 181X, 182X, 183X, 184X, 185X, 186X, 187X, 188X, 189X, 190X, 191, 192XX, 193X, 194X, 195X, 196X, 197X, 19X8, 199X, 200X, 201X, 202X, 203X, 204X, 205X, 206X, 207X, 208X, 209X

398.91, 402.01, 402.11, 402.91, 404.01,

Z85X, Z08X, C00X, C01X, C02X, C03X, C04X, C05X, C06X, C07X, C08X, C09X, C10X, C11X, C12X, C13X, C14X, C15X, C16X, C17X, C18X, C19X, C20X, C21X, C22X, C23X, C24X, C25X, C26X, C30X, C31X, C32X, C33X, C34X, C37X, C38X, C39X, C40X, C41X, C43X, C44X, C4AX, C45X, C46X, C47X, C48X, C49X, C50X, C51X, C52X, C53X, C54X, C55X, C56X, C57X, C58X, C60X, C61X, C62X, C63X, C64X, C65X, C66X, C67X, C68X, C69X, C70X, C71X, C72X, C73X, C74X, C75X, C76X, C77X, C78X, C79X, C80X, C7AX, C7BX, C82X, C83X, C84X, C85X, C86X, C88X, C90X, C91X, C92X, C93X, C94X, C95X, C96X

109.81, I11.0, I13.0, I13.2, 150, 150.X, 197.13X, P29.0 404.03, 404.11, 404.13, 404.91, 404.93, 429.0, 428.1, 428.20, 428.21, 428.22, 428.23, 428.30, 428.31, 428.32, 428.33, 428.40, 428.41, $428.42,428.43,428.9$

585X, 586X, 403X, 404X, 249.40, 250.41, 250.41, 285.21X, E87.91X, V56.1X, V56.2X, V56.31X, V56.32X, V45.11X, V45.12X, 996.56X, 996.68X, 996.81X
N18X, N19X, I12X, I13X, E08.22X, E09.22X, E10.22X, E11.22X, E13.22X, D63.1X, O10.2X, O10.3X, Y84.1X, Z49X, Z99.2X, Z91.15X, T85.611X, T85.621, T85.631, T85.71X, T86.12X

\footnotetext{
We defined comorbidity cases as cases where an ICD code for one of the following conditions was documented at or prior to the service date and time of the encounter at which a patient tested positive for SARS-CoV-2 infection. A patient who did not have an ICD code for these conditions at or prior to the service date and time of that encounter was considered a negative case for that condition. ICD, International Classification of Diseases; ICD-9-CM, International Classification of Diseases, Ninth Revision, Clinical Modification; ICD-10CM, International Classification of Diseases, Tenth Revision, Clinical Modification.
} 
Table S4 Primary outcome case definitions and codes

\begin{tabular}{|c|c|}
\hline $\begin{array}{l}\text { Primary } \\
\text { outcome }\end{array}$ & Codes/case definitions \\
\hline \multirow[t]{2}{*}{ Death } & $\begin{array}{l}\text { A status of "deceased" (yes/no) is documented for each patient in the dataset. We defined a death case as a patient who } \\
\text { was documented as deceased AND whose encounter noted a discharge disposition of "Expired." We defined a non-death } \\
\text { case as a patient who was not documented in the dataset as deceased }\end{array}$ \\
\hline & $\begin{array}{l}\text { Note: An adjustment was made to some encounters, to account for the fact that some health systems document ER } \\
\text { encounters that are associated with subsequent inpatient stays as two separate encounters (i.e., an ER encounter and an } \\
\text { inpatient encounter), even when those encounters reflect a single episode of care. If the service date of an ER encounter } \\
\text { occurred less than or equal to } 48 \text { hours prior to the service date of an inpatient encounter, we merged the ER encounter } \\
\text { with the subsequent inpatient encounter. Any patient who had a discharge disposition of "Expired" for one of those two } \\
\text { "joined" encounters was considered a death case }\end{array}$ \\
\hline \multirow[t]{2}{*}{ Intubation } & $\begin{array}{l}\text { ICD-10 Procedure Codes: OBH13EZ, OBH17EZ, OBH18EZ, 5A1935Z, 5A1955Z CPT codes: 31500, 94003, 94002, 94004, } \\
\text { 33946, 33947, 33949, 33952, 33953, 33954, 33955, 33966, 33969, 36822 } \\
\text { ICD-10 diagnosis code: T88.4X }\end{array}$ \\
\hline & $\begin{array}{l}\text { Note: An adjustment was made to some encounters, to account for the fact that some health systems document ER } \\
\text { encounters that are associated with subsequent inpatient stays as two separate encounters (i.e., an ER encounter and an } \\
\text { inpatient encounter), even when those encounters reflect a single episode of care. If the service date of an ER encounter } \\
\text { occurred less than or equal to } 48 \text { hours prior to the service date of an inpatient encounter, we merged the ER encounter } \\
\text { with the subsequent inpatient encounter. Any patient who was intubated during one of those two "joined" encounters was } \\
\text { considered an intubation case }\end{array}$ \\
\hline $\begin{array}{l}\text { Hospital } \\
\text { length of stay }\end{array}$ & $\begin{array}{l}\text { For length of stay calculations, an adjustment was made to account for the fact that some health systems document ER } \\
\text { encounters that are associated with subsequent inpatient stays as two separate encounters (i.e., an ER encounter and an } \\
\text { inpatient encounter), even when those encounters reflect a single episode of care. If the service date of an ER encounter } \\
\text { occurred less than or equal to } 48 \text { hours prior to the service date of an inpatient encounter, we merged the ER encounter } \\
\text { with the inpatient encounter. We considered the following encounter types to be inpatient encounters: (I) "admitted for } \\
\text { observation," (II) "inpatient," or (III) "inpatient hospice care." }\end{array}$ \\
\hline
\end{tabular}

CPT, Current Procedural Terminology; ER, emergency room; ICD-10, International Classification of Diseases, Tenth Revision.

Table S5 Medication categories and associated medication names

\begin{tabular}{ll}
\hline Medication category & Medication names (generic) \\
\hline Proton pump inhibitors & esomeprazole, lansoprazole, dexlansoprazole, omeprazole, pantoprazole, rabeprazole \\
H2 blockers & ranitidine, famotidine, cimetidine, nizatidine \\
\hline
\end{tabular}

H2 blocker, histamine 2 receptor agonist.

Table S6 Medication names and search terms

\begin{tabular}{|c|c|}
\hline Generic medication name & Medication Search Terms (case insensitive; asterisk = wildcard character) \\
\hline Esomeprazole & *esomeprazole*, "nexium, " vimovo* \\
\hline Lansoprazole/dexlansoprazole & 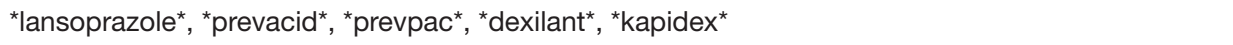 \\
\hline Omeprazole & omeprazole*, " prilosec*, *omeclamox", ${ }^{*}$ zegerid", ${ }^{*}$ yosprala*, ${ }^{*}$ talicia* \\
\hline Pantoprazole & *pantoprazole*, "protonix* \\
\hline Rabeprazole & *rabeprazole*, *aciphex* \\
\hline Ranitidine & *ranitidine*, "acid control”, "acid control 75”, "acid reducer”, "taladine*, "wal-zan*, "zantac*, "tritec* \\
\hline Famotidine & $\begin{array}{l}\text { "acid controller", "famotidine*, "heartburn prevention", "heartburn relief”, "leader acid reducer", } \\
\text { "mylanta*, "pepcid”, "dual action complete", "duo fusion", "duexis* }\end{array}$ \\
\hline Cimetidine & *cimetidine*, "tagamet* \\
\hline Nizatidine & *nizatidine*, *axid* (not including *maxidex*) \\
\hline
\end{tabular}

These search terms were identified by using the multum_dnum_reference medication table. This table contains all generic and brand names from the Multum database. 
Table S7 Full-matched patient cohort: covariate means and standardized mean differences

\begin{tabular}{|c|c|c|c|}
\hline Characteristic & $\begin{array}{l}\text { Means: patients with } \geq 1 \\
\text { abnormal liver chemistries }\end{array}$ & $\begin{array}{l}\text { Means: patients with normal } \\
\text { liver chemistries }\end{array}$ & $\begin{array}{l}\text { Standardized mean } \\
\text { difference }\end{array}$ \\
\hline Distance & $6.51 \mathrm{E}-01$ & $6.48 \mathrm{E}-01$ & 0.029 \\
\hline Age & $5.87 \mathrm{E}+01$ & $6.02 \mathrm{E}+01$ & -0.082 \\
\hline Gender, female & 4.69E-01 & 4.65E-01 & 0.008 \\
\hline Gender, male & $5.31 \mathrm{E}-01$ & $5.35 \mathrm{E}-01$ & -0.008 \\
\hline Race/ethnicity, non-Hispanic White & $3.02 \mathrm{E}-01$ & 3.16E-01 & -0.031 \\
\hline Race/ethnicity, non-Hispanic Black & 1.63E-01 & $1.48 \mathrm{E}-01$ & 0.041 \\
\hline Race/ethnicity, AAPI/AIAN/non-Hispanic Other & 7.93E-02 & 8.14E-02 & -0.008 \\
\hline Race/ethnicity, Hispanic & 4.55E-01 & 4.54E-01 & 0.002 \\
\hline Diabetes mellitus, absent & $5.30 \mathrm{E}-01$ & $5.13 \mathrm{E}-01$ & 0.035 \\
\hline Diabetes mellitus, present & 4.70E-01 & 4.87E-01 & -0.035 \\
\hline Chronic obstructive pulmonary disease, absent & $8.72 \mathrm{E}-01$ & $8.64 \mathrm{E}-01$ & 0.024 \\
\hline Chronic obstructive pulmonary disease, present & $1.28 \mathrm{E}-01$ & $1.36 \mathrm{E}-01$ & -0.024 \\
\hline Coronary artery disease, absent & 7.21E-01 & 7.14E-01 & 0.016 \\
\hline Coronary artery disease, present & 2.79E-01 & 2.86E-01 & -0.016 \\
\hline Liver disease, absent & 7.96E-01 & 7.83E-01 & 0.031 \\
\hline Liver disease, present & $2.04 \mathrm{E}-01$ & 2.17E-01 & -0.031 \\
\hline Body mass index & $3.10 \mathrm{E}+01$ & $3.08 \mathrm{E}+01$ & 0.024 \\
\hline PPI prescription within 60 days, absent & $9.78 \mathrm{E}-01$ & $9.75 \mathrm{E}-01$ & 0.017 \\
\hline PPI prescription within 60 days, present & 2.24E-02 & 2.49E-02 & -0.017 \\
\hline H2 blocker prescription within 60 days, absent & $9.93 \mathrm{E}-01$ & $9.95 \mathrm{E}-01$ & -0.029 \\
\hline H2 blocker prescription within 60 days, present & $7.21 \mathrm{E}-03$ & 4.73E-03 & 0.029 \\
\hline Serum albumin & $3.21 \mathrm{E}+00$ & $3.21 \mathrm{E}+00$ & -0.011 \\
\hline Blood type, O+ & 4.79E-01 & 4.83E-01 & -0.008 \\
\hline Blood type, $A+$ & 3.03E-01 & $3.00 \mathrm{E}-01$ & 0.006 \\
\hline Blood type, B+ & $1.12 \mathrm{E}-01$ & $1.16 \mathrm{E}-01$ & -0.013 \\
\hline Blood type, O- & 4.03E-02 & 4.29E-02 & -0.013 \\
\hline Blood type, A- & $3.47 \mathrm{E}-02$ & $2.80 \mathrm{E}-02$ & 0.036 \\
\hline Blood type, $\mathrm{AB}+$ & $2.29 \mathrm{E}-02$ & $2.49 \mathrm{E}-02$ & -0.014 \\
\hline Blood type, B- & $7.88 \mathrm{E}-03$ & 4.51E-03 & 0.038 \\
\hline Blood type, AB- & $5.63 \mathrm{E}-04$ & $2.25 \mathrm{E}-04$ & 0.014 \\
\hline Malignancy, absent & $8.61 \mathrm{E}-01$ & $8.38 \mathrm{E}-01$ & 0.066 \\
\hline Malignancy, present & $1.39 \mathrm{E}-01$ & $1.62 \mathrm{E}-01$ & -0.066 \\
\hline Heart failure, absent & 7.94E-01 & $7.80 \mathrm{E}-01$ & 0.034 \\
\hline Heart failure, present & $2.06 \mathrm{E}-01$ & $2.20 \mathrm{E}-01$ & -0.034 \\
\hline Chronic kidney disease/End-stage renal disease, absent & 7.35E-01 & 7.35E-01 & 0.001 \\
\hline Chronic kidney disease/End-stage renal disease, present & 2.65E-01 & 2.65E-01 & -0.001 \\
\hline $\begin{array}{l}\text { Nicotine dependence or exposure to tobacco smoke, } \\
\text { absent }\end{array}$ & $6.58 \mathrm{E}-01$ & $6.45 \mathrm{E}-01$ & 0.027 \\
\hline $\begin{array}{l}\text { Nicotine dependence or exposure to tobacco smoke, } \\
\text { present }\end{array}$ & $3.42 \mathrm{E}-01$ & $3.55 \mathrm{E}-01$ & -0.027 \\
\hline
\end{tabular}

AAPI, Asian American/Pacific Islander; AIAN, American Indian/Alaska Native; H2 blocker, histamine 2 receptor agonist; PPI, proton pump inhibitor. 